\title{
ACÚMULO DE SUBSTÂNCIAS DE RESERVA EM GRÃOS DE SOJA. I. MATÉRIA SECA, ÓLEO E ÁCIDOS GRAXOS (')
}

\author{
JOÃo PAULO FEUĨ̃ TEIXEIRA $\left({ }^{2,}{ }^{6}\right)$, MARIA TEREZA BARALDI RAMOS $\left({ }^{2,6}\right)$, \\ ROBERTO MACHADO DE MORAES $\left({ }^{3}\right)$, MARIA HELENA FARACO $\left({ }^{4}\right)$ \\ e HIPÓLITO ASSUNÇĀO ANTONIO MASCARENHAS $\left({ }^{5,6}\right.$ )
}

\begin{abstract}
RESUMO
No estudo da dinâmica de acúmulo de matéria seca e lipídios em grãos de soja, foram utilizadas vagens de dez cultivares, nos anos agrícolas de 1978/79 e 1979/ 80. Os grãos foram avaliados semanalmente durante todo o seu período de desenvolvimento, quanto aos teores de matéria seca, ólé e ácidos graxos. Os resultados mostraram que a influência de anos agrícolas sobre o acúmulo de matéria seca e óleo foi devida principalmente às condiçōes do meio verificadas de 20 a 40 dias antes da maturação dos grãos, em 1978/79: $152 \mathrm{~mm}$ de chuva e $22^{\circ} \mathrm{C}$, e em 1979/80:50,8mm de chuva e $25^{\circ} \mathrm{C}$ de temperatura média. A velocidade de acúmulo de matéria seca nos grãos foi maior em 1979/80, porém o total de matéria seca acumulado, menor: os grãos continham $78 \%$ do total de matéria seca acumulada no ano agrícola de 1978/ 79. Para ólco, verificou-se a influência positiva de temperatura e negativa de precipitação pluvial na velocidade de acúmulo dessa substância durante o período de enchimento dos grãos. Para o cv Santa Rosa, utilizado como referência, em 1978/79, os grâos atingiram o maior valor aos 80 dias após o florescimento (DAF) com $22 \%$ de óleo, e 1979/80 atingiu o valor máximo de $23 \%$ aos 43 DAF. A composição do óleo em ácidos graxos variou durante o desenvolvimento dos grãos, tendo os saturados, ao contrário dos insaturados, decrescido. O teor de ácido linoléico apresentou correlaçẫo positiva com o teor de óleo, enquanto os de ácidos linoléico e linolênico se cor-
\end{abstract}

$\left(\begin{array}{l}1 \\ 2\end{array}\right)$ Recebido para publicação em 30 de maio de 1984.

$\left(\begin{array}{l}2 \\ 3\end{array}\right)$ Seção de Fitoquímica, Instituto Agronômico (IAC), Caixa Postal 28, Campinas, SP.

${ }_{4}^{3}$ ) Atualmente no Instituto de Tecnologia de Alimentos (ITAL).

$\left({ }_{5}^{4}\right.$ ) Bióloga. Estagiária da Seção de Fitoquímica. Com bolsa da Fundação Cargill.

$\left({ }_{6}^{5}\right)$ Seção de Leguminosas, IAC.

(6) Com bolsa de suplementação do $\mathrm{CNPq}$. 
relacionaram negativamente com o teor de ácido oléico. O maior teor de óleo e os menores de ácido linoléico e linolênico estiveram correlacionados com temperatura mais elevada e menor precipitação pluvial.

Termos de indexação: grãos de soja; Glycine max (L.) Merrill; acứmulo de substâncias de reserva; óleo; ácidos graxos; matéria seca.

\section{INTRODUÇÃO}

A soja tornou-se uma importante cultura principalmente pela riqueza de seus grãos em óleo e proteína, porém o acúmulo desses componentes químicos e outros durante o desenvolvimento dos grãos é pouco conhecido, não sendo encontrados estudos em nosso meio além de recente publicação de SILVA et alii (1981), referentes ao cultivar Santa Rosa. Esses autores verificaram que o acúmulo de matéria seca em grãos ocorreu sobretudo no período de 37 a 65 dias após a floração.

As variações de temperatura a $20-30$ e $30-40$ dias antes da maturação dos grãos de soja exercem maior influência sobre o acúmulo de óleo do que as ocorridas em outros períodos, segundo observaram HOWELL \& CARTTER (1953, 1958), e FARACO et alii (1982) para o 'Santa Rosa'. Por outro lado, os teores dos ácidos graxos linoléico e linolênico no óleo de grãos de soja apresentam correlação negativa com a temperatura ambiente (HOWELL \& COLLINS, 1957; CHAPMAN et alii, 1976). ROEHN \& PRIVETT (1970) constataram que as maiores variações na composição dos ácidos graxos dos triglicerídeos ocorrem nos primeiros 52 dias após floração (DAF). Considerando todo o período de desenvolvimento, FARACO et alii (1982) observaram uma diminuição dos teores dos ácidos palmítico e linolênico, e aumento dos de ácidos oléico e linoléico, ficando o esteárico praticamente constante. Essas variações resultam da síntese de ácidos graxos insaturados a partir dos ácidos graxos saturados correspondentes, segundo DUTTON \& MOUNTS (1966) e RUBEL et alii (1972).

O objetivo deste trabalho foi a determinação da dinâmica de acúmulô de matéria seca e lipídios durante o desenvolvimento de sementes de soja.

\section{MATERIAL E MÉTODOS}

Foram utilizados frutos de soja (Glycine $\max (\mathrm{L}$.$) Merrill) cultivares$ Santa Rosa, Paraná, Davis, Viçoja, Bossier e UFV-1, no ano agrícola 1978/ 79, e dos cultivares Santa Rosa, IAC-7, IAC-8, IAC-9 e IAC-10, em 1979/80.

As amostragens foram efetuadas durante o desenvolvimento dos frutos e grãos, semanalmente, até a maturação. Para tanto, eram coletadas dez 
plantas e, seus frutos, amostrados em todo o perfil das mesmas, para evitar o efeito da posição da vagem sobre a composição dos grãos, conforme verificado por TEIXEIRA et alii (1982). No laboratório, os frutos foram abertos, separando-se vagens e grãos. Estes foram mantidos em estufa com circulação de ar a $50^{\circ} \mathrm{C}$ durante cinco dias para avaliação de matéria seca, determinando-se, em duplicata, o peso seco e os teores de óleo e ácidos graxos.

O teor de óleo foi determinado através da extração com hexano em extratores soxhlet por oito horas e avaliação gravimétrica (TRIEBOLD \& AURAND, 1963): e ácidos graxos por cromatografia de gás, utilizando coluna com fase líquida DEGS $10 \%$, após a saponificação do óleo e esterificação dos ácidos graxos com $\mathrm{H}_{2} \mathrm{SO}_{4}-\left(\mathrm{NH}_{4}\right) \mathrm{Cl}$ - metanol (HARTMAN\& LAGO, 1973). Os valores percentuais desses compostos foram avaliados empregando-se a altura do pico e o tempo de retenção de cada éster de ácido graxo.

\section{RESULTADOS E DISCUSSÃO}

No quadro 1 são apresentados os dados de acúmulo de matéria seca até o ponto de maturação fisiológica do grão, considerando que ele ocorre quando o grão atinge o maior acúmulo de matéria seca, em miligramas de matéria seca por grão e miligramas de matéria seca por fruto e número de dias após a floração (DAF) necessários para que o maior acúmulo fosse atingido. Como se verifica, o número de dias requeridos para a maturação fisiológica dos grãos varia com cultivares e anos agrícolas. Em 1978/79, os grãos de 'Santa Rosa' atingiram o valor de $180,30 \mathrm{mg}$ de matéria seca (M.S.) por grão aos 65 DAF, enquanto o mesmo cultivar, em 1979/80, atingiu $146,70 \mathrm{mg}$ aos $49 \mathrm{DAF}$, sugerindo que naquele primeiro ano o acúmulo de matéria seca foi mais lento para os diferentes cultivares, embora atingissem na maturação fisiológica um valor médio maior $(195,30 \pm 8,41 \mathrm{mg})$ que em $1979 / 80(152,99 \pm 9,86 \mathrm{mg})$.

Nesse mesmo quadro, são apresentadas as taxas de acúmulo de matéria seca durante o desenvolvimento e enchimento de frutos e grãos dos dez cultivares de soja. Assim, para o ano agricola 1978/79, verifica-se que os cultivares que tiveram maior taxa de acúmulo nos grãos foram 'Davis' e 'Paraná'. Para frutos, houve maior dispersão das taxas, por causa, principalmente, da diferença do número de grãos existentes por fruto: nesse caso, 'Paraná' e 'Davis' apresentaram as taxas mais elevadas. Para 1979/80, embora 'Santa Rosa' apresentasse maior taxa de enchimento de grãos, não se verificou grande diferença entre os cultivares, à exceção do IAC-7, cuja taxa foi somente 1,6mg M.S.grão ${ }^{-1} \cdot$ dia $^{-1}$. Para frutos, destacaram-se pelas maiores taxas 'Santa Rosa', 'IAC-10' e 'IAC-8', ficando com as menores, 'IAC-7' e 'IAC-9'. 
QUADRO 1 - Acúmulo de matéria seca durante o desenvolvimento de frutos e grãos de soja até o ponto de maturação fisiológica destes

\begin{tabular}{|c|c|c|c|c|c|}
\hline \multirow{2}{*}{ Cultivares } & \multirow{2}{*}{ 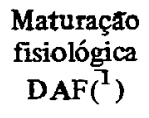 } & \multicolumn{2}{|c|}{ Matéria seca acumulada } & \multicolumn{2}{|c|}{ Taxa de acúmulo } \\
\hline & & Gráos & Frutos & $\operatorname{Gratos}\left({ }^{1}\right)$ & Frutos $\left({ }^{1}\right)$ \\
\hline & & $\mathrm{mg} / \mathrm{grão}$ & $\mathrm{mg} /$ fruto & mg/grão/dia & $\mathrm{mg} /$ fruto/dia \\
\hline \multicolumn{6}{|c|}{ Ano agrícola 1978/1979 } \\
\hline Santa Rosa & 65 & 180,30 & 525,81 & 2,77 & 8,09 \\
\hline Davis & 70 & 237,79 & 803,35 & 3,40 & 11,48 \\
\hline Paraná & 59 & 183,10 & 872,06 & 3,10 & 14,78 \\
\hline Bossier & 71 & 190,29 & 671,71 & 2,68 & 9,46 \\
\hline UFV-1 & 87 & 178,20 & 477,85 & 2,05 & 5,49 \\
\hline Viçoja & 72 & 202,14 & 670,22 & 2,81 & 9,31 \\
\hline Média & - & $195,30 \pm 8,41\left(^{2}\right)$ & $670,17 \pm 56,84$ & $2,80 \pm 0,17$ & $9,77 \pm 1,17$ \\
\hline $\mathrm{CV}(\%)$ & - & 11,53 & 22,76 & 16,22 & 26,76 \\
\hline \multicolumn{6}{|c|}{ Ano agrícola 1979/80 } \\
\hline Santa Rosa & 49 & 146,70 & 459,51 & 2,99 & 9,38 \\
\hline IAC-7 & 71 & 113,74 & 347,32 & 1,60 & 4,89 \\
\hline LAC-8 & 71 & 175,55 & 535,21 & 2,47 & 7,54 \\
\hline IAC-9 & 76 & 170,76 & 439,62 & 2,25 & 5,58 \\
\hline IAC-10 & 56 & 158,18 & 496,05 & 2,82 & 8,86 \\
\hline Média & - & $152,99 \pm 9,86$ & $455,54 \pm 28,26$ & $2,42 \pm 0,22$ & $7,29 \pm 0,77$ \\
\hline $\mathrm{CV}(\%)$ & - & 16,12 & 15,51 & 22,47 & 26,51 \\
\hline
\end{tabular}

$\left({ }^{1}\right)$ DAF $=$ dias após floração. $\left({ }^{2}\right) \bar{X} \pm \sqrt{\frac{s^{2}}{n}}$.

Nos quadros 2 e 3, observa-se que o 'Santa Rosa' nos dois anos agrícolas não apresentou variação no teor finnal de óleo, porém isso ocorreu durante o desenvolvimento dos grãos nos dois anos de cultivo. Em 1978/79, o acúmulo de óleo nos grãos deu-se mais lentamente, acompanhando o acúmulo đe matéria seca, atingindo o maior valor aos 81 DAF com $21,77 \%$ de óleo. Ao contrário, em 1979/80, verificou-se maior acúmulo relativo de óleo nos grãos, atingindo o valor máximo, 22,64\%, aos 43 DAF.

Analisando a precipitação pluvial e temperatura média durante todo o desenvolvimento dos grãos nos dois anos agrícolas, não se verificaram variações acentuadas (Quadro 4) capazes de esclarecer as diferenças ocorridas no acámulo de óleo nos grãos. À semelhança do verificado por HOWELL \& CARTTER (1953) e FARACO et alii (1982), os quadros 2 e 3 revelam que é 
QUADRO 2 - Acúmulo de óleo em grãos de cultivares de soja desenvolvidos no ano agricola de $1978 / 79$

DAF $\left({ }^{1}\right) \quad$ Oleo $\quad$ DAF $\quad$ Oleo

$\begin{array}{cc}\text { M.S.\% mg/grao } & \text { M.S.\% } \mathrm{mg} / \mathrm{grä} \\ \text { Santa Rosa } & \text { Bossier }\end{array}$

\begin{tabular}{rrrrrr}
29 & 11,17 & 1,26 & 15 & 9,95 & 1,10 \\
36 & 12,43 & 3,24 & 21 & 11,53 & 3,47 \\
44 & 14,33 & 7,38 & 28 & 9,87 & 4,02 \\
52 & 15,79 & 18,15 & 35 & 10,64 & 6,94 \\
58 & 15,88 & 23,49 & 42 & 15,79 & 14,75 \\
65 & 16,89 & 32,68 & 49 & 16,78 & 22,05 \\
74 & 19,77 & 32,67 & 59 & 18,85 & 30,21 \\
81 & 21,77 & 38,54 & 64 & 19,62 & 34,35 \\
85 & 20,65 & 31,88 & 71 & 18,15 & 34,53 \\
94 & 21,13 & 39,83 & 80 & 20,77 & 37,69 \\
\hline
\end{tabular}

Paraná

Davis

$\begin{array}{rrrrrr}32 & 8,80 & 3,14 & 36 & 13,44 & 5,11 \\ 38 & 11,60 & 9,74 & 42 & 11,75 & 8,96 \\ 45 & 10,22 & 9,70 & 49 & 12,21 & 14,41 \\ 52 & 17,52 & 23,11 & 56 & 16,54 & 23,72 \\ 59 & 20,79 & 38,06 & 63 & 19,29 & 32,69 \\ 66 & 22,15 & 39,19 & 70 & 21,96 & 52,19 \\ 76 & 20,20 & 36,70 & 80 & 22,31 & 48,21\end{array}$

Viçoja

UFV-1

\begin{tabular}{rrrrrr}
20 & 12,14 & 3,72 & 28 & 8,42 & 3,01 \\
27 & 15,88 & 4,88 & 32 & 9,14 & 5,62 \\
34 & 14,08 & 11,52 & 39 & 9,45 & 5,49 \\
44 & 11,13 & 14,15 & 48 & 8,50 & 10,87 \\
49 & 10,67 & 16,18 & 55 & 12,95 & 18,78 \\
56 & 17,67 & 36,14 & 59 & 14,45 & 23,02 \\
65 & 20,75 & 43,56 & 68 & 18,01 & - \\
72 & 28,49 & 43,86 & 87 & 18,63 & 33,19 \\
76 & 19,85 & 40,18 & & & \\
\hline
\end{tabular}

( 1 ) DAF = Dias após floração. 
no período aproximado de 20 a 40 dias antes da maturação dos grãos que ocorreram os maiores acréscimos no teor do óleo, quando se pode perceber melhor a ação das condiçбes climáticas estudadas influenciando o acúmulo de 6́leo nos grãos. Nesse período, em 1979/80, houve um déficit de chuvas e a média de temperatura foi mais elevada, ao contrário do verificado em 1978/79 (Quadro 4). Provavelmente, as condiçбes reinantes em 1979/80, a 20-40 dias antes da maturaçđo dos grãos, aceleraram o acamulo de 6́leo nos

QUADRO 3 - Acúmulo de b́leo em gráos de cultivares de soja desenvolvidos no ano agrícola de $1979 / 80$

\begin{tabular}{|c|c|c|c|c|c|}
\hline \multirow[t]{2}{*}{$\operatorname{DAF}\left({ }^{1}\right)$} & \multicolumn{2}{|c|}{ Oleo } & \multirow[t]{2}{*}{ DAF } & \multicolumn{2}{|c|}{ Óleo } \\
\hline & M.S.\% & mg/grao & & M.S.\% & $\mathrm{mg} / \mathrm{grão}$ \\
\hline \multicolumn{4}{|c|}{ IAC-7 } & \multicolumn{2}{|c|}{ IAC-10 } \\
\hline $\begin{array}{l}44 \\
50 \\
57 \\
63 \\
71 \\
78\end{array}$ & $\begin{array}{l}14,38 \\
13,38 \\
18,50 \\
19,31 \\
20,07 \\
20,98\end{array}$ & $\begin{array}{r}3,55 \\
5,40 \\
13,32 \\
17,56 \\
22,82 \\
23,49\end{array}$ & $\begin{array}{l}37 \\
43 \\
50 \\
56 \\
64 \\
71\end{array}$ & $\begin{array}{l}17,27 \\
20,11 \\
19,66 \\
22,14 \\
22,45 \\
22,18\end{array}$ & $\begin{array}{r}9,75 \\
18,37 \\
26,19 \\
35,02 \\
34,78 \\
35,66\end{array}$ \\
\hline \multicolumn{4}{|c|}{ IAC-8 } & \multicolumn{2}{|c|}{ IAC-9 } \\
\hline $\begin{array}{l}44 \\
50 \\
57 \\
63 \\
71 \\
78 \\
84\end{array}$ & $\begin{array}{l}13,12 \\
19,38 \\
19,48 \\
20,42 \\
21,33 \\
21,08 \\
21,66\end{array}$ & $\begin{array}{r}5,40 \\
16,93 \\
22,25 \\
30,64 \\
37,42 \\
33,60 \\
35,91\end{array}$ & $\begin{array}{l}42 \\
48 \\
55 \\
61 \\
69 \\
76 \\
85\end{array}$ & $\begin{array}{l}10,46 \\
12,85 \\
19,47 \\
21,48 \\
20,34 \\
22,18 \\
21,29\end{array}$ & $\begin{array}{r}1,33 \\
4,15 \\
13,64 \\
24,00 \\
27,66 \\
37,87 \\
27,91\end{array}$ \\
\hline
\end{tabular}

\section{Santa Rosa}

$\begin{array}{rrr}15 & 3,67 & 0,09 \\ 22 & 9,93 & 1,73 \\ 30 & 14,89 & 6,21 \\ 36 & 21,95 & 18,23 \\ 43 & 22,64 & 32,65 \\ 49 & 21,92 & 32,15 \\ 57 & 22,31 & 30,64 \\ 64 & 21,56 & 30,28\end{array}$

( ${ }^{1}$ ) DAF = Dias após floração. 
grãos em desenvolvimento. A conversão de açacares em óleo e o aumento da respiração em temperaturas mais elevadas favoráveis à deposição de maior quantidade de 6leo, podem ocasionar diminuição de peso final do grão de soja, segundo HOWELL \& CARTTER (1958). Neste trabalho (Quadro 1), verificou-se que os grãos produzidos em 1979/80 atingiram aproximadamente $78 \%$ do peso daqueles de $1978 / 79$, o que concorda com o encontrado por aqueles autores. Aparentemente, todos os outros cultivares seguiram essa mesma tendência do 'Santa Rosa'. Assim, as variaçóes entre os materiais colhidos no mesmo ano agrícola para teor de bleo podem ser atribuidas às diferenças genotípicas dos cultivares.

QUADRO 4 - Total de chuvas e temperatura média ocorrida nos períodos de amostragem e de 20 a 40 dias antes da maturaçáo do cultivar Santa Rosa nos anos agrícolas de $1978 / 79$ e $1979 / 80$

\begin{tabular}{lccc}
\hline Ano agrícola & Período & Chuva & Temperatura média \\
\hline & & $\mathrm{mm}$ & ${ }^{\circ} \mathrm{C}$ \\
$1978 / 79\left({ }^{1}\right)$ & $22 / 1$ a $15 / 4$ & 410 & 23,0 \\
$\left.1979 / 80{ }^{1}\right)$ & $13 / 2$ a $17 / 4$ & 333 & 23,8 \\
$1978 / 79\left(^{2}\right)$ & $16 / 3$ a $05 / 4$ & 152 & 22,2 \\
$\left.1979 / 80{ }^{2}\right)$ & $07 / 3$ a $28 / 3$ & 51 & 25,0 \\
\hline
\end{tabular}

$\left({ }^{1}\right)$ Perfodo de desenvolvimento dos graos. $\left({ }^{2}\right)$ Vinte a quarenta dias antes da maturaçáo.

Durante o desenvolvimento dos grãos de soja dos dez cultivares estudados, verificaram-se alteraçôes na composição do óleo acumulado. Para todos os cultivares, houve um decréscimo nos teores de ácidos palmítico, esteárico, oléico e linolênico, e um acréscimo no teor de ácido linoléico. Para o 'Santa Rosa', o linoléico apresentou correlação positiva com o teor de óleo nos grãos, sendo os coeficientes de 0,80 e 0,98 para os anos de 1978/79 e $1979 / 80$, respectivamente, significativos ao nível de $1 \%$ pelo teste $t$. No mesmo cultivar (Quadro 5), pode-se observar que para o ano agrícola de $1979 / 80$, os teores finais dos ácidos linoléico e linolênico foram menores e, o de oléico, maior, do que os valores para esses ácidos graxos encontrados em 1978/79. Essa informação confirma dados obtidos por CHAPMAN et alii (1976), mostrando que temperaturas mais elevadas são responsáveis por acámulo de óleo em grãos de soja com menor quantidade de ácidos graxos linoléico e linolênico. Confirma, da mesma forma CHU \& SHELDON (1979), 
QUADRO 5 - Teores de ácidos graxos no óleo do cultivar Santa Rosa durante o perfodo de desenvolvimento dos grãos nos anos agrícolas de 1978/79 e 1979/80

\begin{tabular}{|c|c|c|c|c|c|c|c|}
\hline \multirow{2}{*}{ Ano } & \multirow{2}{*}{$\operatorname{DAF}\left({ }^{1}\right)$} & \multicolumn{6}{|c|}{ Ácidos graxos } \\
\hline & & Mirŕstico & Palmítico & Esteárico & Oléico & Linoléico & Linolênico \\
\hline \multirow[b]{2}{*}{$1978 / 79$} & & \multicolumn{6}{|c|}{ Santa Rosa } \\
\hline & $\begin{array}{l}29 \\
36 \\
44 \\
52 \\
58 \\
65 \\
74 \\
81 \\
85 \\
94\end{array}$ & $\begin{array}{l}0,07 \\
0,23 \\
0,31 \\
0,47 \\
0,36 \\
0,21 \\
0,47 \\
0,28 \\
0,23 \\
0,41\end{array}$ & $\begin{array}{r}14,73 \\
12,81 \\
12,87 \\
10,64 \\
10,65 \\
11,76 \\
10,84 \\
9,42 \\
10,63 \\
10,78\end{array}$ & $\begin{array}{l}4,22 \\
3,62 \\
4,37 \\
3,42 \\
3,84 \\
3,52 \\
3,62 \\
2,90 \\
3,23 \\
3,42\end{array}$ & $\begin{array}{l}15,77 \\
24,74 \\
24,98 \\
21,94 \\
22,86 \\
21,69 \\
22,11 \\
19,75 \\
19,46 \\
22,51\end{array}$ & $\begin{array}{l}52,81 \\
49,46 \\
48,81 \\
56,11 \\
55,23 \\
56,90 \\
56,21 \\
61,46 \\
58,58 \\
56,04\end{array}$ & $\begin{array}{r}12,41 \\
9,14 \\
8,66 \\
7,42 \\
7,06 \\
5,91 \\
6,74 \\
6,19 \\
7,67 \\
6,84\end{array}$ \\
\hline
\end{tabular}

\section{Santa Rosa}

$\begin{array}{rrrrrrrr}1979 / 80 & 15 & 2,02 & 26,14 & 9,74 & 13,19 & 28,81 & 20,10 \\ & 22 & 1,01 & 20,47 & 5,68 & 31,54 & 34,71 & 6,60 \\ & 30 & 0,14 & 14,04 & 3,92 & 28,66 & 46,30 & 6,94 \\ & 36 & 0,15 & 12,70 & 3,79 & 27,79 & 50,45 & 5,11 \\ & 43 & 0,05 & 12,04 & 3,37 & 26,44 & 52,52 & 5,58 \\ & 49 & 0,08 & 12,02 & 3,42 & 24,47 & 54,01 & 6,01 \\ & 57 & 0,44 & 10,93 & 3,54 & 25,04 & 53,92 & 6,12 \\ & 64 & 0,07 & 11,30 & 3,59 & 25,27 & 53,81 & 5,96\end{array}$

( ${ }^{1}$ ) DAF $=$ Dias após floração. 
que encontraram aumento de ácidos graxos insaturados quando as plantas de soja eram cultivadas em solo irrigado, mostrando, ainda, que o aumento relativo dos ácidos linoléico e linolênico implicou sempre em descréscimo do teor de ácido oléico.

Para os cultivares estudados (Quadros 5 a 10), a soma dos ácidos graxos saturados na maturação diminuiu à medida que a dos insaturados aumentou, evidenciando a sintese de ácidos graxos insaturados a partir do correspondente saturado, como verificado por DUTTON \& MOUNTS (1966), INKPEN \& QUACKENBUSH (1969) e RUBEL et alii (1972).

QUADRO 6 - Teores de ácidos graxos no óleo dos cultivares Paraná e Davis durante o período de desenvolvimento dos graos no ano agrícola de 1978/79

\begin{tabular}{|c|c|c|c|c|c|c|}
\hline \multirow{2}{*}{$\mathrm{DAF}^{\left({ }^{1}\right)}$} & \multicolumn{6}{|c|}{ Åcidos graxos } \\
\hline & Mirístico & Palmítico & Esteárico & Oléico & Linoléico & Linolênico \\
\hline & \multicolumn{6}{|c|}{$-\%$} \\
\hline & \multicolumn{6}{|c|}{ Paraná } \\
\hline 32 & 1,35 & 18,32 & 5,42 & 27,23 & 37,82 & 9,32 \\
\hline 38 & 1,35 & 17,03 & 5,92 & 33,09 & 35,22 & 6,91 \\
\hline 45 & 1,32 & 19,18 & 7,23 & 28,31 & 37,02 & 6,42 \\
\hline 52 & 0,82 & 8,26 & 4,28 & 21,95 & 56,54 & 7,77 \\
\hline 59 & 0,64 & 11,15 & 3,83 & 20,24 & 55,53 & 8,35 \\
\hline 66 & 0,34 & 10,68 & 3,56 & 18,31 & 57,84 & 8,89 \\
\hline 76 & 0,44 & 10,70 & 3,61 & 18,79 & 57,27 & 9,00 \\
\hline
\end{tabular}

Davis

$\begin{array}{lllllll}36 & 0,34 & 13,88 & 5,03 & 31,78 & 42,30 & 6,35 \\ 42 & 0,66 & 17,12 & 6,30 & 38,20 & 31,99 & 5,09 \\ 49 & 0,69 & 19,41 & 7,24 & 41,12 & 27,68 & 3,16 \\ 56 & 0,25 & 11,51 & 4,11 & 22,94 & 54,53 & 6,38 \\ 63 & 0,83 & 11,26 & 3,74 & 21,00 & 56,54 & 6,47 \\ 70 & 0,44 & 11,32 & 3,57 & 20,58 & 57,33 & 6,46 \\ 80 & 0,53 & 10,52 & 3,28 & 19,37 & 58,61 & 7,36\end{array}$

( ${ }^{1}$ ) DAF = Dias após floração. 
QUADRO 7 - Teores de ácidos graxos no óleo dos cultivares Bossier e Viçoja durante o período de desenvolvimento dos gráos no ano agrícola de 1978/79.

\begin{tabular}{|c|c|c|c|c|c|c|}
\hline \multirow{2}{*}{$\operatorname{DAF}^{\left({ }^{1}\right)}$} & \multicolumn{6}{|c|}{ Ácidos graxos } \\
\hline & Mirístico & Palmrtico & Esteárico & Oléico & Linoléico & Linolênico \\
\hline
\end{tabular}

$\%$

\section{Bossier}

\begin{tabular}{lrllllr}
15 & 0,55 & 17,10 & 5,04 & 18,51 & 43,08 & 15,13 \\
21 & 0,30 & 15,04 & 5,21 & 25,35 & 43,55 & 10,05 \\
28 & 0,29 & 18,31 & 6,95 & 33,46 & 34,60 & 5,75 \\
35 & 0,48 & 16,41 & 6,27 & 30,49 & 39,86 & 5,99 \\
42 & 0,22 & 15,49 & 6,26 & 30,02 & 42,96 & 4,59 \\
49 & 0,14 & 15,30 & 5,19 & 25,38 & 48,85 & 4,76 \\
59 & 0,21 & 11,37 & 4,24 & 23,17 & 54,49 & 6,12 \\
64 & 0,28 & 11,85 & 4,10 & 19,77 & 56,50 & 7,25 \\
71 & 0,20 & 10,80 & 3,67 & 22,10 & 55,76 & 7,27 \\
80 & 0,18 & 11,17 & 4,06 & 24,43 & 54,85 & 4,92 \\
\hline
\end{tabular}

Viçoja

\begin{tabular}{rrrrrrr}
20 & 0,70 & 13,03 & 4,14 & 25,79 & 45,40 & 10,68 \\
27 & 0,31 & 12,17 & 3,84 & 26,89 & 47,67 & 8,66 \\
34 & 1,14 & 19,33 & 6,77 & 40,68 & 27,65 & 3,76 \\
44 & 1,26 & 20,63 & 7,30 & 42,64 & 23,86 & 3,27 \\
49 & 1,46 & 19,44 & 8,07 & 41,14 & 26,66 & 2,50 \\
56 & 0,62 & 16,14 & 5,23 & 31,07 & 43,12 & 3,48 \\
65 & 0,48 & 11,02 & 3,55 & 24,03 & 53,86 & 6,79 \\
72 & 0,47 & 11,73 & 2,74 & 23,30 & 54,64 & 6,76 \\
76 & 0,33 & 10,19 & 3,52 & 25,51 & 52,55 & 6,58 \\
\hline
\end{tabular}

$\left({ }^{1}\right.$ ) DAF = Dias após floração. 
QUADRO 8 - Teores de ácidos graxos no óleo do cultivar UFV-1 durante o período de desenvolvimento dos graos no ano agrícola de 1978/79

\begin{tabular}{llll}
\hline & \multicolumn{4}{c}{ Ácidos graxos } \\
\cline { 2 - 5 } & $\left.{ }^{1}\right)$ & \multicolumn{4}{c}{ Mirístico } & Palmitico Esteárico Oléico Linoléico Linolênico
\end{tabular}
$\%$

UFV-1

\begin{tabular}{lllllll}
28 & 0,91 & 20,05 & 5,83 & 34,63 & 33,32 & 4,64 \\
32 & 0,37 & 18,90 & 6,52 & 38,47 & 30,23 & 4,94 \\
39 & 0,94 & 18,79 & 6,90 & 36,14 & 31,30 & 5,36 \\
48 & 0,39 & 18,00 & 7,12 & 40,25 & 29,85 & 3,97 \\
55 & 0,42 & 14,16 & 4,97 & 30,35 & 45,34 & 4,37 \\
59 & 0,37 & 11,41 & 3,83 & 23,53 & 53,65 & 6,85 \\
68 & 0,29 & 10,18 & 3,68 & 24,02 & 54,19 & 7,43 \\
87 & 0,31 & 10,57 & 3,82 & 22,00 & 55,39 & 7,48 \\
\hline
\end{tabular}

( ${ }^{1}$ ) DAF $=$ Dias após floração.

QUADRO 9 - Teores de ácidos graxos no 6leo dos cultivares IAC-7 e IAC-8 durante o período de desenvolvimento dos grãos no ano agrícola de 1979/80

\begin{tabular}{lllll}
$\left.\mathrm{DAF}^{(}{ }^{1}\right)$ & \multicolumn{4}{c}{ Ácidos graxos } \\
\cline { 2 - 4 } & Mirístico & Palmítico & Esteárico Oléico & Linoléico Linolènico \\
\hline
\end{tabular}
$\%$

IAC-7

$\begin{array}{lllllll}44 & 0,30 & 13,30 & 4,94 & 23,21 & 48,84 & 9,04 \\ 50 & 0,56 & 11,46 & 5,04 & 24,56 & 49,52 & 8,43 \\ 57 & 0,23 & 11,21 & 4,89 & 25,35 & 50,79 & 7,06 \\ 63 & 0,16 & 10,68 & 4,94 & 24,18 & 52,94 & 6,71 \\ 71 & 0,20 & 11,00 & 4,71 & 23,01 & 53,76 & 6,86 \\ 78 & 0,23 & 10,71 & 4,70 & 22,44 & 54,35 & 7,12\end{array}$

Continua 
QUADRO 9. Conclusão

DAF ${ }^{(1)}$

\section{Ácido graxos}

Mirístico Palmítico Esteárico Oléico Linoléico linolênico

\begin{tabular}{llllrlr}
\hline \multicolumn{7}{c}{ IAC-8 } \\
44 & 0,12 & 12,17 & 4,39 & 22,41 & 49,51 & 11,06 \\
50 & 0,08 & 11,00 & 4,35 & 24,94 & 50,81 & 8,35 \\
57 & 0,12 & 10,78 & 4,38 & 25,95 & 50,82 & 7,61 \\
63 & 0,13 & 10,72 & 4,13 & 24,26 & 52,87 & 7,60 \\
71 & 0,15 & 11,09 & 3,94 & 22,06 & 54,01 & 8,34 \\
78 & 0,16 & 11,02 & 3,82 & 22,29 & 54,19 & 8,11 \\
84 & 0,16 & 10,86 & 3,83 & 22,08 & 54,30 & 8,44 \\
\hline
\end{tabular}

$\left({ }^{1}\right)$ DAF $=$ Dias após floração.

QUADRO 10 - Teores de ácidos graxos no oleo dos cultivares IAC-9 e IAC-10 durante o período de desenvolvimento dos graos no ano agrícola de 1979/80

$\left.\mathrm{DAF}^{1}\right)$

Ácidos graxos

Mirf́stico Palmftico Esteárico Oléico Linoléico Linolênico

\begin{tabular}{|c|c|c|c|c|c|c|}
\hline \multirow[b]{2}{*}{42} & \multicolumn{6}{|c|}{ IAC-9 } \\
\hline & 1,52 & 18,10 & 5,23 & 22,42 & $42 ; 96$ & 10,26 \\
\hline 48 & 0,70 & 14,96 & 4,55 & 27,39 & 44,10 & 7,97 \\
\hline 55 & 0,25 & 12,64 & 4,16 & 26,09 & 49,93 & 6,57 \\
\hline 61 & 0,20 & 10,84 & 3,51 & 26,28 & 53,30 & 5,62 \\
\hline 69 & 0,22 & 12,03 & 3,57 & 22,98 & 54,92 & 6,05 \\
\hline 76 & 0,23 & 11,53 & 3,40 & 22,56 & 55,37 & 6,47 \\
\hline \multirow[t]{2}{*}{85} & 0,22 & 11,61 & 3,65 & 22,92 & 54,91 & 6,25 \\
\hline & \multicolumn{6}{|c|}{ IAC 10} \\
\hline 37 & 0,14 & 11,23 & 3,83 & 27,63 & 49,33 & 7,66 \\
\hline 43 & 0,17 & 10,31 & 3,57 & 30,63 & 49,04 & 6,15 \\
\hline 50 & 0,30 & 10,03 & 3,45 & 31,98 & 48,68 & 5,35 \\
\hline 56 & 0,17 & 9,96 & 3,13 & 28,67 & 52,30 & 5,46 \\
\hline 64 & 0,18 & 9,91 & 3,13 & 27,73 & 52,99 & 5,85 \\
\hline 71 & 0,13 & 9,82 & 2,97 & 29,44 & 51,43 & 5,86 \\
\hline
\end{tabular}

$\left({ }^{1}\right)$ DAF $=$ Dias após floração. 
ROEHN \& PRIVETT (1970) mostraram que as maiores variaçסes na composição em ácidos graxos do oleo de soja ocorreram até 52 DAF. Neste trabalho, para todos os cultivares estudados, exceto 'Santa Rosa', os ácidos graxos apresentaram teores percentuais praticamente estáveis entre 50 e 60 DAF. Para o 'Santa Rosa', a composição percentual variou com o ano agrícola, tendo-se tornado estável em 1978/79, após 52 DAF, e, em 1979/80, a partir de 36 DAF (Quadro 5).

\section{CONCLUSŌES}

1. O acúmulo de matéria seca e óleo em grãos de soja foi influenciado por anos agrícolas e cultivares.

2. O aumento do perfodo de enchimento de grãos provocou maior acúmulo de matéria seca.

3. Condiçбes de ambiente favoráveis à deposição de óleo relacionaram-se com menor peso seco do grão de soja.

4. Maior teor de oleo e menores de ácidos linoléico e linolênico relacionaram-se com temperaturas mais elevadas.

\section{SUMMARY}

\section{ACCUMULATION OF RESERVE SUBSTANCES IN SOYBEAN SEEDS. I. DRY MATTER, OIL AND FATTY ACIDS}

The dynamics of dry matter and lipids accumulation in seeds of ten cultivars of soybeans during the pod filling stage was studied. Samples were taken at intervals of seven days until maturity during $1978 / 79$ and 1979/80, respectively. Seeds were analysed for dry matter, oil and fatty acids content. Results showed that the cropping seasons affected accumulation, mainly due to climatic conditions 20 to 40 days before maturity. In 1978/79 the average rainfall and temperature during such period were, respectively, $152 \mathrm{~mm}$ and $22.2^{\circ} \mathrm{C}$, and $51 \mathrm{~mm}$ and $25^{\circ} \mathrm{C}$ in $1979 / 80$. The rate of seed dry matter accumulation was higher in 1979/80, although the total dry matter accumulated was lower than in 1978/79. The rate of seed oil accumulation decreased in rainy periods and increased at high temperatures. The seed oil content of cv Santa Rosa, used as reference, reached 22\% at the 80 days after flowering (DAF) in : $1978 / 79$ and $23 \%$ at the 43 DAF in $1979 / 80$, respectively. The fatty acids composition varied during the seed development, when there was a decrease in saturated as opposed to unsaturated fatty acids contents. The linoleic acid content showed positive correlation with oil percentage, whereas linoleic and linolenic acids were negatively correlated with oleic acid content. The highest oil content and the lowest linoleic and linolenic acids content were associated with high temperature and low rainfall.

Index terms: soybean seeds; Glycine max (L.) Merrill; accumulation of reserve substances; oil; fatty acids; dry matter. 


\section{REFERÊNCIAS BIBLIOGRÁFICAS}

CHAPMAN JR., G.W.; ROBERTSON, J.A. \& BURDICK, D. Chemical composition and lipoxygenase activity in soybeans as affected by genotype and environment. Journal of American Oil Chemists Society, 53:5456, 1976.

CHU, W.S. \& SHELDON, V.L. Soybean oil quality as influenced by planting site and variety. Journal of American Oil Chemists Society, 56:71-73. 1979.

DUTTON, H.J. \& MOUNTS, T.L. Desaturation of fatty acids in seeds of higher plants. Journal of Lipid Research, 7:221-225, 1966.

FARACO, M.H.; MORAES, R.M.; TEIXEIRA, J.P.F.; SILVA, M.T.R.; MASCARENHAS, H.A.A. Influência de anos agrícolas sobre a composição e acúmulo de óleo em grãos de soja CV Santa Rosa. In: SEMINÁRIO NACIONAL DE PESQUISA DE SOJA. 2., Brasília, 1981. Anais. Londrina, EMBRAPA/CNPSo, 1982. v. 1, p.544553.

HARTMAN, L \& LAGO, R.C.A. Rapid preparation on fatty acid methyl esters from lipids. Laboratory Practice, London, 20:475-476, 1973.

HOWELL, R.W. \& CARTTER, J.L. Physiological factors affecting composition of soybeans. I - Response of oil and other constituents of soybeans to temperature under controlled conditions. Agronomy Journal, 45:526$528,1953$.

Physiological factors affecting composition of soybeans. II - Response of oil and other constituents of soybeans to temperature under controlled conditions. Agronomy Journal, 50:664-667, 1958b.

\& COLLINS, F.I. Factors affecting linolenic acid and linoleic acid content of soybean oil. Agronomy Journal, 49:593-597, 1957.

INKPEN, J.A. \& QUACKENBUSH, F.W. Desaturation of palmitate and stearate by cell-free fractions from soybean cotyledons. Lipids, 4:539$543,1969$.

ROEHN, J.N. \& PRIVETT, O.S. Changes in the structure of soybeans triglycerides during maturation. Lipids, 5:353-358, 1970.

RUBEL, A.; RINNE, R.W. \& CANVIN, D.T. Protein, oil and fatty acids in developing soybean seeds. Crop Science, 12:739-741, 1972.

SILVA, M.T.R. da; MORAES, R.M. de \& TEIXEIRA, J.P.F. Variação da composição química de grãos de soja 'Santa Rosa' durante o seu desenvolvimento. Bragantia, Campinas, 40:12-19, 1981. 
TEIXEIRA, J.P.F.; FARACO, M.H.; SILVA, M.T.R. da; MORAES, R.M. de; MASCARENHAS, H.A.A.; MIRANDA, M.A.C. Variação na composição química de grãos de soja em função da posição das vagens na planta. In: SEMINÁRIO NACIONAL DE PESQUISA DA SOJA, 2., Brasília, 1981. Anais. Londrina, EMBRAPA/CNPSo, 1982. v. 1, p. 689-697. TRIEBOLD, H.O. \& AURAND, L.N. Food composition and analysis. New York, Ed. Litton Educational Publishing, 1963. 497p. 